\title{
Hepatitis B Prevalence among Pregnant Women in Central and West Nile regions of Uganda: Is there a Need to prioritize Prevention of Mother to Child hepatitis B transmission?
}

Joan Nankya-Mutyoba ( $\square$ eron.jm@hotmail.com )

Makerere University College of Health Sciences https://orcid.org/0000-0002-0661-5933

Jim Aizire

Department of Epidemiology, Bloomberg School of Public Health, Johns Hopkins University

Fredrick Makumbi

Department of Epidemiology \& Biostatistics, School of Public Health, College of Health Sciences, Makerere University

Lynn Atuyambe

Department of Community Health \& Behavioral Sciences, School of Public Health, College of Health

Sciences, Makerere University

Gregory Kirk

Department of Epidemiology, Bloomberg School of Public Health, Johns Hopkins University

\section{Ponsiano Ocama}

Department of Medicine, School of Medicine, College of Health Sciences, Makerere University

Research article

Keywords: Hepatitis B, Pregnant women, Prevalence

Posted Date: July 9th, 2019

DOI: https://doi.org/10.21203/rs.2.11150/v1

License: (c) (i) This work is licensed under a Creative Commons Attribution 4.0 International License. Read Full License 


\section{Abstract}

Introduction Within sub-Saharan Africa (SSA), the burden of chronic hepatitis B (HBV) is unacceptably high in several countries including Uganda. Elimination of HBV in the context of inadequate resources and several competing health issues, faces challenges including limited data on disease burden in important population sub-groups. In order to optimize available resources, reliable data on HBV among pregnant women is useful to guide policies on prevention. This study estimated HBV prevalence and related factors among pregnant women in Central and West Nile regions of Uganda Methods Using a twostage sampling approach, we selected a random sample of 310 pregnant women, 18 years or older from public health facility antenatal clinics in central and west Nile, North-western Uganda. Consenting women were interviewed to obtain data on HBV vaccination status, HIV status, selected sexual and lifestyle factors and socio-demographic information. In addition, they underwent phlebotomy to obtain blood for testing for hepatitis B surface antigen, (HBsAg) antibodies to the surface antigen (anti-HBs), and antibodies to the core (anti-HBc), as indicators of chronic infection, prior exposure, and susceptibility (anti-HBs $<10 \mathrm{mIU} / \mathrm{mL}$ ), respectively. Results Out of 310 women, prevalence of chronic HBV infection was $6.2 \%$. Prevalence in the West Nile region was notably higher than in the Central region $(11.0 \%$ vs. $1.3 \%), p<0.001$. In both regions, majority of pregnant women (61\% West Nile region, $76 \%$ Central region) were still susceptible to HBV. Overall, proportion who had been tested for HBV and those who reported having been vaccinated was only $5.8 \%$ and $11.3 \%$ respectively. Conclusion Our findings reveal the burden of HBV in Ugandan pregnant women is still high, with marked regional differences in disease prevalence, and poor levels of HBV testing and vaccination. These data suggest that HBV prevention programs and policies in resource-limited settings like Uganda may need to consider the differential HBV prevalence, as optimizing HBV prevention services in higher prevalence regions may provide greater impact and thereby align with the WHO recommendation on HBV elimination strategy in SSA.

\section{Background}

The global public health burden of hepatitis B virus (HBV) is currently recognized to be high particularly in Asia and sub-Saharan Africa (SSA)(1,2). Approximately 257 million individuals are chronically infected with HBV (1) and both HBV and hepatitis $C$ virus are leading causes of liver disease, including liver cancer (3). In high burden regions, perinatal transmission is the largest contributor to chronic HBV infection, especially when it occurs during early neonatal life (4). Because of this burden, the world health assembly responded with a strategy for global elimination of viral hepatitis as a major public health problem, by 2030 (5). Elimination is seen as feasible, given the availability of a vaccine against HBV and increasing accessibility to effective antivirals which can prevent progression from chronic HBV infection to liver cirrhosis and liver cancer(6-8).

The HBV vaccine, which is highly efficacious, as well as viral suppression using effective antiviral drug regimens, provide an unparalleled moment to reduce the burden of HBV-associated liver cancer. Yet vaccine uptake and coverage with antivirals remains much lower than needed in most of sub-Saharan Africa, where fewer than $5 \%$ of persons infected are not aware of their infection, and fewer than $1 \%$ of 
those needing antivirals do not access them (9). Reducing the burden, to achieve HBV elimination goals, will require multiple, well-coordinated and targeted approaches, particularly among important subpopulations.

Pregnant women constitute an important sub-population regarding HBV control and elimination in high burden settings, due to the risk of mother to child HBV transmission (10), that results in early life chronic HBV infections. Moreover, studies in West Africa have linked perinatally-acquired HBV to liver complications, including liver cancer $(11,12)$. Yet in most of these settings, including Uganda, pregnant populations continue to be excluded from national HBV control strategies. Currently in Uganda, like most of SSA, services including antenatal HBV education, universal screening or vaccination for HBV among pregnant women and the HBV birth dose vaccination are not standard of care (13-16).

Epidemiologic studies on HBV among pregnant populations in Uganda are still too limited to provide an accurate measure of HBV prevalence and transmission risk, for purposes of informing best approach to HBV control in pregnant women and preventing mother to child HBV transmission. Only one study in the past decade, for instance, has estimated prevalence of hepatitis B e antigen (HBeAg) in a Ugandan hospital-based pregnant population, and found $15 \%$ of HBV surface antigen positive women, also positive for HBeAg (17). However, the study did not gather information on HBV testing, or vaccination, both useful measures of maternal HBV care practices. Equally important is data on the main drivers of HBV transmission risk, in order to optimize prevention interventions. Studies elsewhere have documented exposure through unprotected sex (18), unscreened blood products and unsterile medical injections (19) as major risk factors as well as on-going horizontal transmission particularly in early childhood $(10,20)$. The data currently available from SSA is inadequate to provide evidence in support of more rigorous strategies to prevent MTCT of HBV (21). This study therefore aimed to assess prevalence of HBV infection, susceptibility and immunity to infection, prevention and associated factors among pregnant women in two regions with a differing general adult population HBV prevalence (22). The purpose is to better understand HBV prevalence and susceptibility in the antenatal populations of the two regions in order to inform current approaches to HBV control and elimination among pregnant women in Uganda.

\section{Methods}

\section{Study setting and design}

The survey was conducted in Government-funded public health facilities at the level of Health center III and IV located in central region districts of Kampala and Wakiso, and in Arua Hospital. Arua Hospital is a regional referral hospital, situated in Arua district, approximately 300 miles north-west from Kampala city, in the West Nile region of north-western Uganda. The hospital has a bed capacity of 323 beds and it serves a population of roughly 782,077 covering districts of West Nile and parts of Northern Uganda (23). It receives about 153,451 out-patients and its antenatal client volume is estimated to be 5,149 antenatal per year. Kampala district is mostly urban, Wakiso district is $92 \%$ rural, with rapid urbanization. Kiswa health center III and Kasangati health center IV were the recruitment sites for the central region. Both 
these primary care health units receive high patient volumes, averaging $850-1,000$ antenatal clients per month (24).

\section{Study sample}

The sample size for this study utilized the formula by Kish Leslie (25) for estimating a single population proportion $\left[n=z^{2} p q / d^{2}\right.$ ] where $z$, the standard normal deviate at $95 \%$ confidence level takes the value of $1.96, p$, the prevalence of hepatitis $B$ of $10 \%(22)$; $d$, the desired level of precision. This yielded a sample size of 155 , inclusive of an estimated non-response fraction of $10 \%$. Therefore 155 participants were enrolled from the central and the West Nile regions respectively, for a total of 310 participants. Systematic sampling was used to select participants, whereby every $5^{\text {th }}$ eligible participant was approached for consent to be recruited into the study. Recruitment was spread evenly within each antenatal clinic day, until the total number was accrued.

\section{Participant eligibility, procedures and data collection}

To be included in the study, participants had to be at least 18 years old, pregnant, and registered for antenatal care in the health facility registry. Women otherwise fulfilling inclusion criteria were excluded from participation if they did not provide consent, were too sick to participate or to complete all required study procedures, including undergoing phlebotomy to provide a blood sample. Those willing to participate were then screened for eligibility and, if eligible, informed consent was sought from them by the study staff. Study staff interviewed participants and documented data on socio-demographic factors (age, region of residence, education, marital status, religion, occupation, history of testing for HBV (Yes/No), prior vaccination against HBV (Yes/No), number of doses of HBV vaccine received, sexual behaviour (number of lifetime sex partners) plus other health and lifestyle factors(smoking (Yes/No), alcohol use(Yes/No), history of jaundice (Yes/No), history of injection drug use(Yes/No), ever having been diagnosed with: liver cirrhosis(Yes/No), Schistosomiasis(Yes/No), chronic kidney disease(Yes/No) or diabetes(Yes/No). Clinical information on HIV status (infected/not infected), parity and history of abortion was abstracted from medical files of participants.

\section{Blood draws and laboratory_procedures}

Each participant provided a blood sample equivalent to $9 \mathrm{ml}$ for hepatitis B virus assays. Blood was collected in EDTA vacutainer tubes according to written study procedures. The tests were performed in accordance with the manufacturer's protocol. Quantitative serological assays for hepatitis B surface antigen (HBsAg,) anti bodies to the surface antigen (anti-HBs) and antibodies to the core antigen (anti$\mathrm{HBc}$ ) were done. WHO guidelines (26) on cut off values were used to determine presence of antibody 
levels corresponding to previous immunity (anti-HBs $\geq 10 \mathrm{mlU} / \mathrm{mL}$ ). Assays were done at MBN Clinical Laboratories, an internationally certified laboratory.

\section{Ethical Issues:}

All study staff received training from the online NIH course on protection of human research subjects and specific training on Uganda National Council for Science and technology (UNCST) national guidelines (27). Potential participants were approached during the general antenatal session and provided with information about the study, and those willing to participate underwent a consenting process. Only those willing and who provided written informed consent were recruited into the study. All participants received pre-testing counseling provided by trained counselors in small groups, prior to blood draws, but post-test counseling was offered individually and privately. This study protocol received review and clearance from Makerere University School of Public Health's higher degrees, Research and Ethics Committee and UNCST.

\section{Data analysis.}

Data were double-entered in excel, cleaned and exported into Stata. Analysis was done using Stata, version 14(StataCorp; College station, TX, 77845 USA). Data exploration was done and categories created. Descriptive summary statistics were generated as mean (standard deviation (SD)) for continuous variables, and proportions for categorical variables. The main outcome variable was chronic hepatitis B infection, defined as a single positive hepatitis B surface antigen (HBsAg) test result. Other outcomes of interest were immunity due to prior exposure (HBsAg test negative and positive for antibodies to the surface antigen) and susceptibility to HBV (defined as HBsAg negative and hepatitis B surface antibody negative). Chronic infection, immunity to infection and susceptibility to infection were treated as binary variables. Distribution of HBV infection by age groups, region of residence, religion, education, marital status, occupation, lifetime sexual partners, HIV status and other lifestyle and health factors was performed. Differences in proportions were tested using Pearson's chi-square test $p$-values and Fisher's exact test $p$-values, where appropriate. A two-tailed $p$-value of $\leq 0.05$ was used for statistical significance.

\section{Results}

\section{Participant characteristics}

A total of 310 pregnant women participated in the study, aged 18 to 42 years. The mean age was 25.9 $(S D \pm 4.9)$ years. About a half $(189 / 310,46.9 \%)$ had attained at least a secondary education, while slightly more than a half were in employment $(165 / 310,53.2 \%)$ and reported to be in a monogamous marital union $(175 / 310,56.5 \%)$. Of the 310 participants, 27 (8.7\%) were infected with HIV, and of these, only 4 
(14.8\%) were not on anti-retroviral medication. None of the HIV infected participants were co-infected with HBV. The other socio-demographic characteristics are shown in table 1.

\section{Markers of HBV infection, susceptibility and immunity to infection}

Overall, out of 310 pregnant women, 19 (6.2\%) had chronic HBV infection, marked by HBV surface antigen positive assays. By region, proportion who were HBV surface antigen positive in the Central region were $1.3 \%(2 / 155)$, but $11 \%(17 / 155)$ in the West Nile region (Figure 1). Proportion who had markers of previously acquired immunity to HBV, either via a naturally acquired infection, or through previous vaccination were $22.6 \%$ and $27.7 \%$ in the central and northern regions, respectively. Majority of pregnant women in both regions showed markers of susceptibility to HBV, $76 \%$ in the Central and $61 \%$ in the West Nile region.

\section{Participants' hepatitis B testing and vaccination status}

Figure 2 shows proportion of pregnant women who reported having been tested and vaccinated against HBV. Only $5.8 \%$ (18/310) of pregnant women reported having taken a hepatitis B test, and $11.3 \%$ (35/310) reported having been vaccinated against HBV. Of those who reported having been vaccinated, 16 women had received only one vaccine dose, 4 women had received two doses and only 15/35 (43\%) had received all three doses of HBV vaccine.

\section{Association of HBV sero-positivity with clinical, socio-demographic and lifestyle factors}

Table 2 reports the association of hepatitis B infection positivity with socio-demographic, clinical and behavioral lifestyle factors among pregnant women.

As shown on this table, statistically, there was a significant association between HBV sero-positivity and region of residence $(p=0.001)$, type of marital relationship $(p=0.018)$, level of education $(p=0.026)$ and lifetime sexual partners $(p=0.012)$. Conversely, no statistically significant association was found between HBV sero-positivity and age $(p=0.605)$, parity $(p=0.632)$, religion $(p=0.988)$, type of occupation $(p=0.737)$, previous HBV vaccination status $(p=1.00)$, a family history of jaundice $(p=0.722)$ or HIV infection $(p=0.390)$. We further examined distribution of selected correlates of HBV infection by region, and as 
shown in table 3, only proportion of women who self-reported to be in monogamous marriage differed, being higher in the northern region. Distribution of other factors including median age and lifetime sexual partners was similar in both regions.

\section{Discussion}

This study aimed to investigate HBV infection, testing and vaccination among pregnant women attending routine antenatal care in two of four of Uganda's geographic regions, with varying adult HBV population prevalence. Of the two regions analysed, the West Nile region in North-Western Uganda had a much higher HBV infection prevalence of $11 \%$. This prevalence from the West Nile region is not very different that previously reported by Bayo et al (17), 12\% chronic HBV prevalence among pregnant women in two private, not-for-profit hospitals located in the Northern Uganda. Our findings, the first within the past decade to come from obstetric populations of North-Western and Central regions, continue to reflect a pattern of regional disparity in Uganda's HBV burden that was much earlier reported in a national survey (22) conducted more than a decade ago, with the Northern corridor having a much higher prevalence than elsewhere, even within the pregnant population. A plausible factor for a high HBV burden in Northern Uganda seems to stem from a steadily growing refugee population mainly from neighboring South Sudan and the Democratic Republic of Congo. In these countries, large populations of adults and children live in conflict situations and are often unimmunized. South Sudan is a high burden HBV country, which, until very recently, has been without a structured national HBV control program. It is estimated that 1 in every 10 persons in South Sudan is infected with either HBV or hepatitis $C$ virus (28). Our findings also support recent observations in SSA, where the burden of HBV in pregnant sub-populations remains proportionately high in localities with a high HBV population-level endemicity (29-33).

Like studies elsewhere in SSA $(29,34)$, majority of our participants were unaware of their HBV status. Very few pregnant women reported ever having tested for HBV, or having received HBV vaccination. And of those that sought vaccination services, fewer than half completed the required three dose vaccination schedule. Moreover, the women who reported having been tested or vaccinated for HBV received these services from private clinics, and paid privately. This finding may be an indicator of a general lack of awareness about HBV and its prevention. We have previously reported poor HBV knowledge and awareness in this region (35). This may be partially due to sub-optimal, even absent, hepatitis B services for pregnant women in most of SSA $(13,36)$. Without testing pregnant women for HBV, it becomes a challenge, not only to identify infected women who require further follow-up testing to ascertain those eligible for anti-viral treatment, but also to plan for timely birth dose vaccination of newborns of these women. Absence of routine HBV testing for pregnant women in Uganda continues to be a significant barrier to HBV status awareness among pregnant women, which further disables the chain of HBV care.

It is also noteworthy, that none of the HBV infected pregnant women in our study sample had HIV coinfection. Unlike our finding, other studies within the region have reported HIV among HBV infected pregnant women $(37,38)$. Our result might be explained by the fact that all our HIV infected women were already taking ART. Several ART regimens have been shown to be anti-HBV active (39-42), and a recent 
longitudinal analysis in rural Rakai, Uganda, showed that HIV infected adults who were taking ART were less likely to acquire HBV (43). We report an unexpected negative correlation between HBV infection and risky sexual behavior, a finding that we believe to be due to participant under-reporting and social desirability bias, as data on type of marital relationship and lifetime sexual partners were self-reported.

The WHO elimination strategy for HBV in high burden settings (5) prescribes an approach involving understanding the local HBV epidemic, in order to adapt the response to local disease epidemiology. Our descriptive findings lend support to this narrative, by reporting locally-derived data that not only highlights intra-country differences in disease prevalence, but also is suggestive of flexible modalities of maternal and new born HBV prevention, guided by existing disease patterns. The findings suggest a need to intensify HBV prevention efforts among pregnant women in Uganda, particularly antenatal HBV testing in the most-affected regions, plus effective follow-up and appropriate management of infected women to prevent mother to child HBV transmission. The available resources could be optimally used, to afford atrisk pregnant women an opportunity to know their HBV status, and their newborns to receive a birth dose of HBV vaccine.

Note is taken, regarding limitations of this study. The cross-sectional and descriptive nature of the study limits strong inference regarding the observed associations. Also, much of the data on sociodemographic and behavioral variables were self-reported, and as such, liable to subjectivity, and the bias thereof. In addition, the few numbers of HBV infected cases meant that we were unable to adequately assess factors associated with HBV infection. Studies with larger sample sizes, and designed to evaluate HBV incidence and risk factors may increase our understanding of HBV risk factors in both regions, thereby, enabling implementation of the appropriate interventions in affected regions. Nonetheless, this work contains useful information on current HBV prevalence in two regions, and can ably contribute to local evidence to support policy options.

Strategies to control and eventually eliminate the health threat of HBV, will need to include prevention of mother to child transmission. This may entail introduction of testing and vaccination for pregnant women. Our findings reveal very low levels of HBV testing and vaccination among pregnant women even in high-endemic regions of Uganda, implying a missed opportunity to offer HBV prevention services to women who interface with the health system.

In conclusion, we have identified high HBV prevalence among pregnant women, with significant regional differences in prevalence, differences that highlight the need for flexible policy options in order to strengthen and speed-up HBV elimination actions. These findings underscore a need to intensify and optimize HBV prevention efforts among antenatal populations, testing pregnant women and implementing interventions to prevent mother to child HBV transmission, within the context of less than sufficient resources.

\section{Declarations}


This work would not have been possible, without the funders of this study, who included (1) Consortium for Advanced Research Training in Africa (CARTA). CARTA is jointly led by the African Population and Health Research Center and the University of the Witwatersrand and funded by the Wellcome Trust (UK) (Grant No: 087547/Z/08/Z),(2) The HIV \& Hepatocellular Carcinoma Research Program in Uganda (H2U), a U-54 Consortium grant from National Cancer Institute of the US's National Institutes of Health.

\section{Availability of data and materials}

Datasets used for analysis and writing of this manuscript are available from the corresponding author, on reasonable request.

\section{Author's contributions}

JNM conceptualized the study, participated in collecting data, analysis and writing the first draft. PO, FM, LA \& GDK supported conceptualization of the study. PO JA FM \& GDK contributed to analysis and writing of the manuscript. All authors read and approved the final manuscript.

\section{Ethics approval and consent to participate}

This study received approval from Makerere University School of Public Health Higher Degrees, Research and Ethics Committee (IRB Number 00005876; FWA Number 00011353). All eligible study participants went through a consenting process and provided written informed consent in English or one of the local languages (Luganda in central region, and Lugbara in northern region) to participate in the study.

\section{Competing interests}

The authors declare that they have no competing interests

\section{References}

1. WHO. Global hepatitis report Geneva: World Health Organization 2017 [04/06/2019]. Available from: https://www.who.int/hepatitis/publications/global-hepatitis-report2017/en/.

2. Stanaway JD, Flaxman AD, Naghavi M, Fitzmaurice C, Vos T, Abubakar I, et al. The global burden of viral hepatitis from 1990 to 2013: findings from the Global Burden of Disease Study 2013. The Lancet. 2016;388(10049):1081-8.

3. Dienstag JL. Hepatitis B virus infection. New England Journal of Medicine. 2008;359(14):1486-500.

4. Zampino R, Boemio A, Sagnelli C, Alessio L, Adinolfi LE, Sagnelli E, et al. Hepatitis B virus burden in developing countries. World journal of gastroenterology. 2015;21(42):11941.

5. Organization WH. Global health sector strategy on viral hepatitis 2016-2021. Towards ending viral hepatitis. World Health Organization, 2016.

6. Liaw Y-F, Sung JJ, Chow WC, Farrell G, Lee C-Z, Yuen H, et al. Lamivudine for patients with chronic hepatitis B and advanced liver disease. New England Journal of Medicine. 2004;351(15):1521-31. 
7. Wu C-Y, Lin J-T, Ho HJ, Su C-W, Lee T-Y, Wang S-Y, et al. Association of nucleos (t) ide analogue therapy with reduced risk of hepatocellular carcinoma in patients with chronic hepatitis B-a nationwide cohort study. Gastroenterology. 2014;147(1):143-51. e5.

8. Papatheodoridis GV, Chan HL-Y, Hansen BE, Janssen HL, Lampertico P. Risk of hepatocellular carcinoma in chronic hepatitis B: assessment and modification with current antiviral therapy. Journal of hepatology. 2015;62(4):956-67.

9. Organization WH. Prevention, Care and Treatment of Viral Hepatitis in the African Region: Framework for Action, 2016-2020. Regional Office for Africa, editor. 2016.

10. Shimakawa Y, Bottomley C, Njie R, Mendy M. The association between maternal hepatitis B e antigen status, as a proxy for perinatal transmission, and the risk of hepatitis B e antigenaemia in Gambian children. BMC public health. 2014;14(1):532.

11. Shimakawa Y, Lemoine M, Njai HF, Bottomley C, Ndow G, Goldin RD, et al. Natural history of chronic HBV infection in West Africa: a longitudinal population-based study from The Gambia. Gut. 2016;65(12):2007-16.

12. Shimakawa Y, Lemoine M, Bottomley C, Njai HF, Ndow G, Jatta A, et al. Birth order and risk of hepatocellular carcinoma in chronic carriers of hepatitis B virus: a case-control study in The Gambia. Liver international. 2015;35(10):2318-26.

13. Razavi-Shearer D, Gamkrelidze I, Nguyen MH, Chen D-S, Van Damme P, Abbas Z, et al. Global prevalence, treatment, and prevention of hepatitis B virus infection in 2016: a modelling study. The lancet Gastroenterology \& hepatology. 2018;3(6):383-403.

14. Howell J, Lemoine M, Thursz M. Prevention of materno-foetal transmission of hepatitis B in subSaharan Africa: the evidence, current practice and future challenges. Journal of viral hepatitis. 2014;21(6):381-96.

15. Tamandjou CR, Maponga TG, Chotun N, Preiser W, Andersson MI. Is hepatitis B birth dose vaccine needed in Africa? The Pan African medical journal. 2017;27(Suppl 3).

16. Bodo B, Malande OO. Delayed introduction of the birth dose of Hepatitis B vaccine in EPI programs in East Africa: a missed opportunity for combating vertical transmission of Hepatitis B. The Pan African Medical Journal. 2017;27(Suppl 3).

17. Bayo P, Ochola E, Oleo C, Mwaka AD. High prevalence of hepatitis B virus infection among pregnant women attending antenatal care: a cross-sectional study in two hospitals in northern Uganda. BMJ open. 2014;4(11):e005889.

18. Inoue T, Tanaka Y. Hepatitis B virus and its sexually transmitted infection-an update. Microbial cell. 2016;3(9):420.

19. Simonsen L, Kane A, Lloyd J, Zaffran M, Kane M. Unsafe injections in the developing world and transmission of bloodborne pathogens: a review. Bulletin of the World Health Organization. 1999;77(10):789.

20. BERNIER RH, SAMPLINER R, GERETY R, TABOR E, HAMILTON F, NATHANSON N. Hepatitis B infection in households of chronic carriers of hepatitis $B$ surface antigen: factors associated with prevalence 
of infection. American journal of epidemiology. 1982;116(2):199-211.

21. Organization WH. Guidelines for the Prevention Care and Treatment of Persons with Chronic Hepatitis B Infection: Mar-15: World Health Organization; 2015.

22. Bwogi J, Braka F, Makumbi I, Mishra V, Bakamutumaho B, Nanyunja M, et al. Hepatitis B infection is highly endemic in Uganda: findings from a national serosurvey. African health sciences. 2009;9(2).

23. USAID. Strengthening Uganda's Systems for Treating AIDS Nationally (SUSTAIN) Report Internet2017 [20-June-2018]. Available from: http://sustainuganda.org/sites/sustainuganda.org/files/Arua.

24. MOH. Hospital and health center survey, 2014: Uganda Ministry of Health 2015 [5-Febraury-2018]. Available from: http://www.who.int/healthinfo/systems/SARA_H_UGA_Results_2014.pdf.

25. Kish L. Survey Sampling. A Wiley Interscience Publication, Illustrated Edition, J Wiley. 1965;60:1-643.

26. Organization WH. WHO guidelines on hepatitis B and C testing: World Health Organization; 2017.

27. UNCST. National guidelines for research involving humans internet: Uganda National Council for Science and Technology; 2017 [5th-June-2019]. Available from:

https://uncst.go.ug/download/national-guidelines-for-research-involving-humans/.

28. WHO. Efforts to eliminate viral hepatitis in South Sudan Internet: World Health Organization 2019 [17th-May-2019]. Available from: https://www.afro.who.int/news/world-health-organizationsupports-ministry-health-strengthen-efforts-eliminate-viral.

29. Noubiap JJN, Nansseu JRN, Ndoula ST, Bigna JJR, Jingi AM, Fokom-Domgue J. Prevalence, infectivity and correlates of hepatitis $B$ virus infection among pregnant women in a rural district of the Far North Region of Cameroon. BMC Public Health. 2015;15(1):454.

30. Bittaye M, Idoko P, Ekele BA, Obed SA, Nyan O. Hepatitis B virus sero-prevalence amongst pregnant women in the Gambia. BMC infectious diseases. 2019;19(1):259.

31. Kirbak ALS. Sero-prevalence for Hepatitis B virus among pregnant women attending antenatal clinic in Juba Teaching Hospital, Republic of South Sudan. The Pan African medical journal. 2017;26.

32. Umare A, Seyoum B, Gobena T, Mariyam TH. Hepatitis B virus infections and associated factors among pregnant women attending antenatal Care Clinic at Deder Hospital, eastern Ethiopia. PLoS One. 2016;11(11):e0166936.

33. Adjei CA, Atibila F, Apiribu F, Ahordzor F, Attafuah PA, Ansah-Nyarko M, et al. Hepatitis B Infection among Parturient Women in Peri-Urban Ghana. The American journal of tropical medicine and hygiene. 2018;99(6):1469-74.

34. Amsalu A, Ferede G, Eshetie S, Tadewos A, Assegu D. Prevalence, Infectivity, and Associated Risk Factors of Hepatitis B Virus among Pregnant Women in Yirgalem Hospital, Ethiopia: Implication of Screening to Control Mother-to-Child Transmission. Journal of pregnancy. 2018;2018.

35. Nankya-Mutyoba J, Aizire J, Makumbi F, Atuyambe L, Ocama P, Kirk GD. Correlates of hepatitis B awareness and disease-specific knowledge among pregnant women in Northern and Central Uganda: a cross-sectional study. Hepatology, Medicine and Policy. 2018;3(1):14. 
36. Dionne-Odom J, Njei B, Tita AT. Elimination of Vertical Transmission of Hepatitis B in Africa: AReview of Available Tools and New Opportunities. Clinical therapeutics. 2018.

37. Thumbiran NV, Moodley D, Parboosing R, Moodley P. Hepatitis B and HIV co-infection in pregnant women: indication for routine antenatal hepatitis B virus screening in a high HIV prevalence setting. SAMJ: South African Medical Journal. 2014;104(4):307-9.

38. Mutagoma M, Balisanga $H$, Malamba SS, Sebuhoro D, Remera E, Riedel DJ, et al. Hepatitis B virus and HIV co-infection among pregnant women in Rwanda. BMC infectious diseases. 2017;17(1):618.

39. Benhamou Y, Fleury H, Trimoulet P, Pellegrin I, Urbinelli R, Katlama C, et al. Anti-hepatitis B virus efficacy of tenofovir disoproxil fumarate in HIV-infected patients. Hepatology. 2006;43(3):548-55.

40. Gatanaga H, Hayashida T, Tanuma J, Oka S. Prophylactic effect of antiretroviral therapy on hepatitis B virus infection. Clinical infectious diseases. 2013;56(12):1812-9.

41. Heuft MM, Houba SM, van den Berk GE, van de Haere TS, van Dam AP, Dijksman LM, et al. Protective effect of hepatitis B virus-active antiretroviral therapy against primary hepatitis B virus infection. Aids. 2014;28(7):999-1005.

42. Shilaih M, Marzel A, Scherrer A, Braun D, Kovari H, Rougemont M. Swiss HIV Cohort Study A; Swiss HIV Cohort Study. Dually active HIV/HBV antiretrovirals as protection against incident hepatitis $B$ infections: potential for prophylaxis. J Infect Dis. 2016;214:599-606.

43. Seremba E, Ssempijja V, Kalibbala S, Gray RH, Wawer MJ, Nalugoda F, et al. Hepatitis B incidence and prevention with antiretroviral therapy among HIV positive individuals in Rakai, Uganda. AIDS (London, England). 2017;31(6):781.

\section{Tables}

Table 1. Participant socio-demographic and clinical characteristics 


\begin{tabular}{|c|c|c|}
\hline Characteristic & $\begin{array}{c}\text { Frequency } \\
(\mathrm{N}=310)\end{array}$ & Percent (\%) \\
\hline \multicolumn{3}{|l|}{ Age group (years) } \\
\hline$\leq 19$ & 30 & 9.7 \\
\hline $20-24$ & 102 & 32.9 \\
\hline $25-29$ & 96 & 31.0 \\
\hline $30-34$ & 47 & 15.2 \\
\hline$\geq 35$ & 35 & 11.2 \\
\hline Age (years): Mean (SD) & \multicolumn{2}{|c|}{$25.8(4.94)$} \\
\hline \multicolumn{3}{|l|}{ Education Level } \\
\hline Primary or lower & 175 & 43.42 \\
\hline Secondary & 189 & 46.90 \\
\hline Post-secondary & 39 & 9.68 \\
\hline \multicolumn{3}{|l|}{ Tribe } \\
\hline Lugbara & 115 & 37.1 \\
\hline Ganda & 74 & 23.9 \\
\hline Others & 121 & 39.0 \\
\hline \multicolumn{3}{|l|}{ Region of residence } \\
\hline West-Nile & 155 & 50.0 \\
\hline Central & 155 & 50.0 \\
\hline \multicolumn{3}{|l|}{ Employment status } \\
\hline Employed & 165 & 53.2 \\
\hline Not employed & 145 & 46.8 \\
\hline \multicolumn{3}{|l|}{ Marital status } \\
\hline Single & 24 & 7.7 \\
\hline Co-habiting & 91 & 29.3 \\
\hline Married monogamous & 175 & 56.5 \\
\hline Married Polygamous & 20 & 6.5 \\
\hline \multicolumn{3}{|l|}{ Religion } \\
\hline Roman Catholic & 109 & 35.2 \\
\hline Protestant & 99 & 31.9 \\
\hline Muslim & 65 & 21.0 \\
\hline Others* & 37 & 11.9 \\
\hline \multicolumn{3}{|l|}{ Parity } \\
\hline 0 & 95 & 30.7 \\
\hline $1-3$ & 176 & 56.8 \\
\hline $4+$ & 39 & 12.6 \\
\hline \multicolumn{3}{|l|}{ HIV Status } \\
\hline positive & 27 & 8.7 \\
\hline negative & 283 & 91.3 \\
\hline
\end{tabular}

Table 2. Association of hepatitis B infection with clinical, socio-demographic, behavioral lifestyle factors among pregnant women in Northern and Central Uganda 


\begin{tabular}{|c|c|c|c|c|}
\hline & \multicolumn{2}{|c|}{ HBV status } & \multirow[b]{2}{*}{$\mathrm{X}^{2}$} & \multirow[b]{2}{*}{$p$-value* } \\
\hline & Yes & No & & \\
\hline \multicolumn{5}{|l|}{ Socio-demographic factors } \\
\hline \multicolumn{5}{|l|}{ Age (Years) } \\
\hline$\leq 19$ & $1(5.26)$ & $29(9.97)$ & \multirow{5}{*}{3.3939} & \multirow{5}{*}{0.605} \\
\hline $20-24$ & $6(31.58)$ & $106(36.43)$ & & \\
\hline $25-29$ & $7(36.84)$ & $92(31.62)$ & & \\
\hline $30-34$ & 5 (26.32) & 46 (15.81) & & \\
\hline$\geq 35$ & $0(0.00)$ & 18 (6.19) & & \\
\hline \multicolumn{5}{|l|}{ Region of residence } \\
\hline West Nile & $17(89.47)$ & $138(47.42)$ & \multirow[t]{2}{*}{12.6153} & \multirow[t]{2}{*}{0.001} \\
\hline Central & $2(10.53)$ & $153(52.58)$ & & \\
\hline \multicolumn{5}{|l|}{ Education } \\
\hline$\leq$ Primary & $5(26.32)$ & $122(41.92)$ & \multirow{3}{*}{7.3066} & \multirow{3}{*}{0.026} \\
\hline Secondary & $9(47.37)$ & 145 (49.83) & & \\
\hline Post-secondary & $5(26.32)$ & $24(8.25)$ & & \\
\hline \multicolumn{5}{|l|}{ Religion } \\
\hline Catholic & $7(36.84)$ & $102(35.05)$ & \multirow{3}{*}{0.0251} & \multirow{3}{*}{0.988} \\
\hline Protestant & $8(42.11)$ & $126(43.30)$ & & \\
\hline Muslim & $4(21.05)$ & 63 (21.65) & & \\
\hline \multicolumn{5}{|l|}{ Marital status } \\
\hline Not currently married & $0(0.00)$ & $24(8.25)$ & & \multirow{4}{*}{0.018} \\
\hline Married-monogamous & $16(84.21)$ & $159(54.64)$ & & \\
\hline Married-polygamous & $2(10.53)$ & $18(6.19)$ & & \\
\hline Co-habiting & $1(5.26)$ & $90(30.93)$ & & \\
\hline \multicolumn{5}{|l|}{ Occupation } \\
\hline Farmer & $8(42.11)$ & $86(29.55)$ & & \multirow{5}{*}{0.737} \\
\hline Restaurant \& bar worker & $7(36.84)$ & $140(48.11)$ & & \\
\hline Housewife & $0(0.00)$ & $10(3.44)$ & & \\
\hline Teacher or civil servant & $2(10.53)$ & $25(8.59)$ & & \\
\hline Hairdresser & $2(10.53)$ & $30(10.31)$ & & \\
\hline \multicolumn{5}{|c|}{ Clinical and behavioral factors } \\
\hline \multicolumn{5}{|c|}{ HIV status } \\
\hline Infected & $0(0.00)$ & $27(9.28)$ & & \multirow[b]{2}{*}{0.390} \\
\hline Not infected & $19(100.00)$ & $264(90.72)$ & & \\
\hline parity & & & & \\
\hline 0 & $4(21.05)$ & $91(31.27)$ & & \\
\hline $1-3$ & $12(63.16)$ & $164(56.36)$ & 0.9187 & 0.632 \\
\hline $4+$ & $3(15.79)$ & $36(12.37)$ & & \\
\hline Previously vaccinated for & & & & \\
\hline Yes & $1(5.26)$ & $17(5.84)$ & & \\
\hline No & $18(94.74)$ & 274 (94.16) & 0.0109 & 1.00 \\
\hline Family h/o jaundice & & & & \\
\hline Yes & $3(15.79)$ & $37(12.71)$ & & \\
\hline No & $16(84.21)$ & $254(87.29)$ & 0.1500 & 0.722 \\
\hline Lifetime sexual partners & & & & \\
\hline One & $12(63.16)$ & $97(33.33)$ & & \\
\hline More than one & $7(36.84)$ & $194(66.67)$ & 6.9588 & 0.012 \\
\hline
\end{tabular}

Page $14 / 17$ 


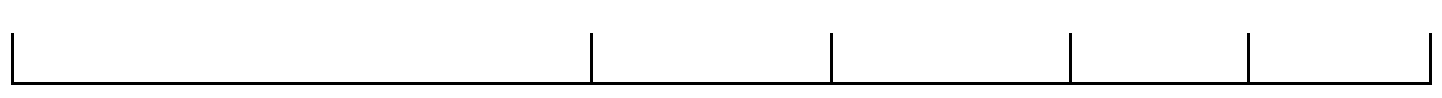

*P-value is for Fisher's exact test.

Table 3. Regional distribution of selected correlates of HBV infection

\begin{tabular}{|l|c|c|}
\hline & Central & North \\
\hline Correlate & & \\
\hline HBsAg positivity (\%) & 1 & 11 \\
\hline Median Age & 25 & 25 \\
\hline >primary education (\%) & 60 & 58 \\
\hline Self-reported monogamous marriage (\%) & 29 & 84 \\
\hline Median lifetime sexual partners & 3 & 2 \\
\hline$>3$ pregnancies (\%) & 19 & 20 \\
\hline
\end{tabular}

\section{Figures}

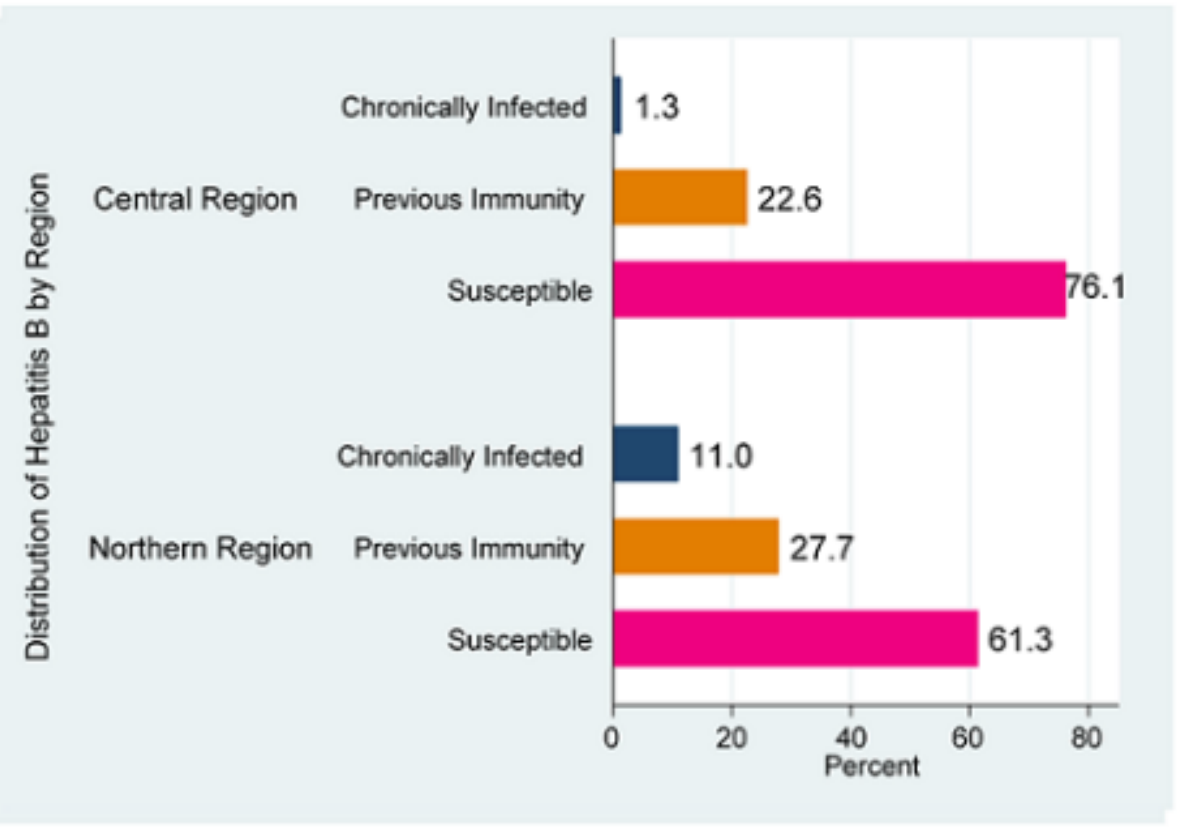

Figure 1

Regional distribution of markers of hepatitis B infection, immunity and susceptibility to infection among pregnant women in Northern and Central Uganda. Chronically infected=proportion of pregnant women who tested positive for HBsAg. Previous Immunity= Proportion of pregnant women who tested negative for HBsAg and had anti-HBS antibody titres greater than $10 \mathrm{lU} / \mathrm{ml}$. Susceptible = proportion of pregnant women who tested negative for HBsAg, and had anti-HBS antibody titres less than $10 \mathrm{IU} / \mathrm{ml}$. 


\section{Ever tested for HBV}

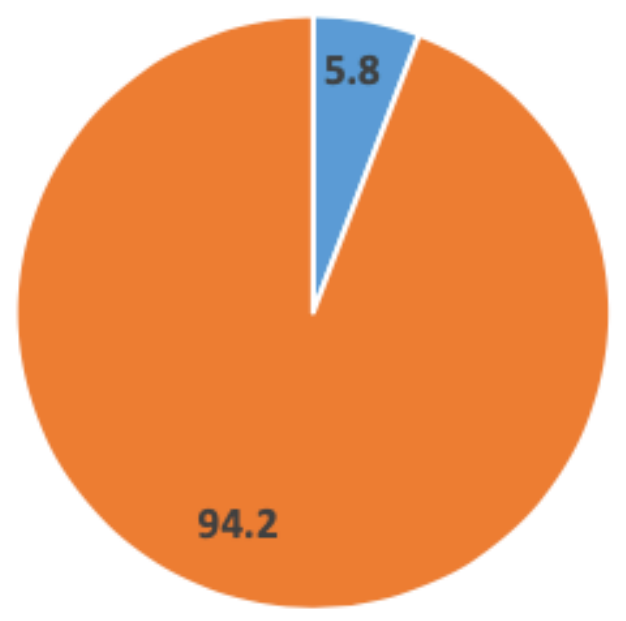

- Yes

No

Showing the proportion of pregnant women who reported ever having tested for HBV.

\section{Figure 2}

Proportion of pregnant women who reported ever having had a hepatitis B test. Yes=proportion of women who reported having tested for HBV; No=proportion of women who reported never having tested for HBV

\section{HBV VACCINATED}

$$
\text { Yes No }
$$

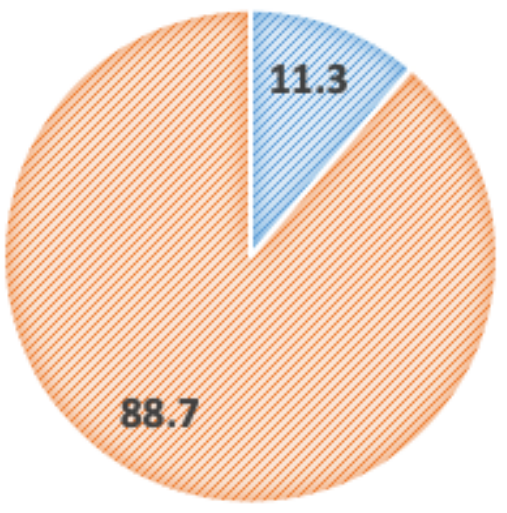

Figure 3 
Proportion of pregnant women who reported having been vaccinated against hepatitis $\mathrm{B}$. Yes=proportion of women who reported having been vaccinated for HBV; No=proportion of women who reported never having been vaccinated for HBV 